\title{
Viperin mRNA is a novel target for the human RNase MRP/RNase $P$ endoribonuclease
}

\author{
Sandy Mattijssen • Ella R. Hinson • \\ Carla Onnekink • Pia Hermanns • Bernhard Zabel • \\ Peter Cresswell • Ger J. M. Pruijn
}

Received: 8 July 2010/Revised: 8 October 2010/Accepted: 13 October 2010/Published online: 30 October 2010

(c) The Author(s) 2010. This article is published with open access at Springerlink.com

\begin{abstract}
RNase MRP is a conserved endoribonuclease, in humans consisting of a 267-nucleotide RNA associated with 7-10 proteins. Mutations in its RNA component lead to several autosomal recessive skeletal dysplasias, including cartilage-hair hypoplasia $(\mathrm{CHH})$. Because the known substrates of mammalian RNase MRP, pre-ribosomal RNA, and RNA involved in mitochondrial DNA
\end{abstract}

Electronic supplementary material The online version of this article (doi:10.1007/s00018-010-0568-3) contains supplementary material, which is available to authorized users.

S. Mattijssen · C. Onnekink · G. J. M. Pruijn ( $\square)$

Department of Biomolecular Chemistry,

Nijmegen Centre for Molecular Life Sciences,

Institute for Molecules and Materials,

Radboud University Nijmegen, PO Box 9101,

6500 HB Nijmegen, The Netherlands

e-mail: g.pruijn@ncmls.ru.nl

S. Mattijssen

e-mail: s.mattijssen@ncmls.ru.nl

E. R. Hinson · P. Cresswell

Department of Immunobiology, Howard Hughes Medical

Institute, Yale University School of Medicine,

New Haven, CT 06520-8011, USA

e-mail: ella@broadinstitute.org

P. Cresswell

e-mail: peter.cresswell@yale.edu

P. Hermanns

Children's Hospital, University of Mainz,

55101 Mainz, Germany

e-mail: hermanns@kinder.klinik.uni-mainz.de

B. Zabel

Department of Pediatrics, Centre for Pediatrics and Adolescent

Medicine, Freiburg University Hospital,

79106 Freiburg, Germany

e-mail: zabel@molgen.medizin.uni-mainz.de replication are not likely involved in $\mathrm{CHH}$, we analyzed the effects of RNase MRP (and the structurally related RNase P) depletion on mRNAs using DNA microarrays. We confirmed the upregulation of the interferon-inducible viperin mRNA by RNAi experiments and this appeared to be independent of the interferon response. We detected two cleavage sites for RNase MRP/RNase $\mathrm{P}$ in the coding sequence of viperin mRNA. This is the first study providing direct evidence for the cleavage of a mRNA by RNase MRP/RNase $\mathrm{P}$ in human cells. Implications for the involvement in the pathophysiology of $\mathrm{CHH}$ are discussed.

Keywords RNase MRP - RNase P · Viperin . Cartilage-hair hypoplasia $\cdot$ Endoribonuclease

\begin{tabular}{|c|c|}
\hline \multicolumn{2}{|c|}{ Abbreviations } \\
\hline TERT & $\begin{array}{l}\text { Telomerase-associated } \\
\text { reverse transcriptase }\end{array}$ \\
\hline $\mathrm{CHH}$ & Cartilage-hair hypoplasia \\
\hline ITS1 & Internal transcribed spacer 1 \\
\hline RMRP & RNase MRP RNA \\
\hline $\mathrm{AD}$ & Anauxetic dysplasia \\
\hline IFN- $\alpha$ & Interferon- $\alpha$ \\
\hline TAM-bodies & $\begin{array}{l}\text { Temporal asymmetric } \\
\text { MRP bodies (TAM-bodies) }\end{array}$ \\
\hline
\end{tabular}

\section{Introduction}

The RNase MRP complex is a ubiquitously expressed essential eukaryotic ribonucleoprotein particle consisting of an RNA component and at least seven proteins (hPop1, hPop5, Rpp20, Rpp25, Rpp30, Rpp38, and Rpp40) [1-3]. 
Three additional proteins are associated with at least a subset of RNase MRP particles: Rpp14, Rpp21 and Rpp29 (hPop4) [2]. RNase MRP is localized primarily in the nucleolus and functions as an endoribonuclease. It is responsible for the generation of the RNA primer that is needed for mitochondrial DNA replication [4], mediates cleavage of the internal transcribed spacer 1 sequence in pre-rRNA, a step in the maturation of rRNA [5], and, in yeast, is required for entry of the precursor rRNA into the canonical processing pathway [6]. In addition, RNase MRP has been implicated in the cell cycle as a result of its capacity to cleave the $5^{\prime} \mathrm{UTR}$ of the cyclin-B2 mRNA [7]. Interestingly, it was recently reported that the RNA component of human RNase MRP, RMRP, forms a complex with the telomerase-associated reverse transcriptase (TERT) [8]. The TERT-RMRP complex exhibits RNA-dependent RNA polymerase activity and produces dsRNAs that are processed into siRNAs by Dicer. One of these siRNAs is directed against the RMRP itself. This way the level of RNase MRP RNA is controlled by the association with TERT via a negative-feedback mechanism [8].

So far, there is no substrate recognition sequence identified for RNase MRP. Secondary and tertiary structural elements are believed to play an important role in the substrate selection by RNase MRP.

Human RNase MRP shares all of its known protein components with RNase P, an evolutionary related endoribonuclease that cleaves the $5^{\prime}$ leader of pre-tRNA, and thus is involved in tRNA maturation [9]. In addition, human RNase $\mathrm{P}$ has been demonstrated to play a role in transcription by polymerase I and III [10, 11]. Bacterial RNase P consists of a RNA component (M1 RNA) and the protein C5. Throughout evolution from prokaryotes to eukaryotes, RNase $\mathrm{P}$ acquired an increasing amount of protein subunits [12]. The human RNase P complex contains at least ten associated proteins.

The human genetic disorder CHH (OMIM250250) [13] is caused by mutations in the RMRP gene [14]. $\mathrm{CHH}$ is inherited in an autosomal recessive manner and patients are characterized by a short stature, hypoplastic hair, and short limbs. In addition, they show a predisposition to lymphomas and other cancer types (primarily hematopoietic), Hirschsprung's disease, bronchiectasis, childhood anemia and suffer from a defective T-cell immunity [15-20]. $\mathrm{CHH}$-associated mutations are either located in the transcribed sequence or in the promoter region of the RMRP gene. So far, more than 70 different $\mathrm{CHH}$-associated mutations have been identified in the 267-nt-long coding region. Between the TATA box and the transcription initiation site, 25 different insertions, duplications, and triplications have been reported [21]. Promoter mutations lead to a diminished or abrogated synthesis of RNase MRP RNA [14]. CHH patients either have a combination of two RNase MRP RNA mutations in both alleles or a combination of a RNase MRP RNA mutation in one allele and a promoter mutation in the other allele, although recently a patient has been reported that carries a combination of two promoter mutations [22]. RMRP mutations lead to a very large heterogeneity in clinical phenotypes, even between family members with the same mutations [23, 24]. In addition to $\mathrm{CHH}, \mathrm{RMRP}$ mutations have also been found in anauxetic dysplasia (AD, MIM \#607095). AD patients suffer from mild mental retardation and hypodontia and display a shorter stature than $\mathrm{CHH}$ patients [21, 25].

The aim of this study was to identify mRNA targets of human RNase MRP. RNase MRP levels were reduced by siRNA-mediated knock-down of its protein subunits and a global mRNA analysis revealed the upregulation of a.o. the viperin mRNA. The upregulation of viperin was confirmed at both the mRNA and protein level. The results are consistent with the direct cleavage of the viperin mRNA by RNase MRP.

\section{Materials and methods}

Cell culture and reagents

HEp-2 and HeLa were maintained in DMEM + Glutamax supplemented with $10 \%$ heat-inactivated fetal calf serum (FCS) in a humidified $37^{\circ} \mathrm{C}, 5 \% \mathrm{CO}_{2}$ incubator. We purchased Interferon- $\alpha$ A/D and poly(I:C) from Sigma.

\section{Antibodies}

Monoclonal antibodies used: Rpp20-specific antibody (IFII, Modiquest), GST-specific antibody (2A9, Modiquest), $\gamma$-tubulin-specific antibody (GTU-88, Abcam) and viperin-specific antibody (MaP.VIP) [26]. Polyclonal rabbit sera against hPop1, Rpp25, and Rpp40 were a kind gift of Sidney Altman. Polyclonal rabbit sera against hPop4 and U3-55K were described previously [27, 28].

Immunoblotting

For immunoblot analysis, proteins were separated by SDS-PAGE and transferred to nitrocellulose membranes by electroblotting. As secondary antibodies, we used the IRDye 800CW Goat Anti-Mouse Secondary Antibody (LiCOR Biosciences) and IRDye 800CW Goat Anti-Rabbit Secondary Antibody (LiCOR Biosciences). We used the Odyssey imaging system (LiCOR Biosciences) for imaging and quantifying of signals. 


\section{RNA interference}

The siRNAs against Rpp20, Rpp25 and hMtr4 were published previously [29, 30]. We purchased the siRNAs against hPop1 (5'-GAAUUUAACCGUAGACAAAd TdT-3'), Rpp40 (5'-CCUUAAACUUGGAUUCUAAdT $\left.\mathrm{dT}-3^{\prime}\right)$ and EGFP (5'-CGAGAAGCGCGAUCACAUGdT $\mathrm{dT}-3^{\prime}$ ) from Eurogentec.

For a typical siRNA experiment in 6-well plates, $1.25 \times 10^{5}$ cells were transfected with 20 pmol of siRNA using Oligofectamine reagent (Invitrogen) according to the manufacturer's instructions with the exception that the medium contains $10 \%$ FCS during transfection. Cells were harvested $48 \mathrm{~h}$ after siRNA transfection.

\section{Transfection}

The pcDNA3.1 constructs containing the coding region of human viperin or the coding region flanked by the $5^{\prime}$ and $3^{\prime}$-UTRs were generated by PCR amplification using genespecific primers (GenBank Accession Number NM_08 0657) containing EcoRI and BamHI restriction sites and cDNA from human foreskin fibroblasts as a template. The purified PCR products were digested with EcoRI and $B a m \mathrm{HI}$ and cloned into the EcoRI and BamHI restriction sites of pcDNA3.1.

We transfected HeLa cells with the viperin constructs and the pEBG plasmid encoding GST [31] (transfection control) using FuGENE 6 (Roche) according to the manufacturer's instructions. Twenty-four hours after transfection with plasmids, the cells were treated with the siRNAs as described above.

In vitro activity assays

PCR was performed to generate the RNA substrates for in vitro transcription by T7 RNA polymerase, using the following primers. For viperin 151-250: 5'-GGGTAAT ACGACTCACTATAGGGCTGGTCCTGAGAGGGCC-3' and 5'-TGCACTGGCGAGTGAAGTGATAGTTGACGC3'; for viperin 401-500: 5'-GGGTAATACGACTCA CTATAGGGAATACCTGGGCAAGTTG-3' and $5^{\prime}$-TGG AACCACCTCTCCCG-3'; for viperin 451-550: $5^{\prime}$-GGGT AATACGACTCACTATAGGGAGCGTGAGCATCGTG AGC-3' and 5'-CAAAGCTGTCACAGGAG-3'; for viperin 751-850: 5'-GGGTAATACGACTCACTATAGGGC TCTTAATTGAGGGTG- $3^{\prime}$ and $5^{\prime}$-TGTGGCGCTCCAAG AATCTTTCAAATTC- $3^{\prime}$ and for viperin 851-950: $5^{\prime}-\mathrm{G}$ GGTAATACGACTCACTATAGGGAAGAAGTGTCCT GCTTG- $3^{\prime}$ and 5'-CGTCCCTTTCTACAGTTC- $3^{\prime}$. The resulting templates were in vitro transcribed by T7 RNA polymerase using ${ }^{32} \mathrm{P}$-labeled UTP. For the pre-tRNA substrate the yeast suppressor precursor tRNA ${ }^{\text {Ser }}$ (pSupS1) plasmid [32] was linearized with TaqI and in vitro transcribed by SP6 RNA polymerase in the presence of ${ }^{32}$ P-labeled UTP.

Antibodies were coupled to Protein-A agarose beads, which were used for immunoprecipitation of RNase $\mathrm{MRP} / \mathrm{P}$ from HEp-2 cell extracts as described elsewhere [2]. $12.5 \mu \mathrm{l}$ of $2 \times$ cleavage buffer (40 mM HEPES-KOH, pH 7.6, $20 \mathrm{mM} \mathrm{MgCl}_{2}, 100 \mathrm{mM} \mathrm{KCl}, 2 \mathrm{mM}$ DTT, and $100 \mu \mathrm{g} / \mathrm{ml}$ BSA) was added to the immunoprecipitates still attached to the beads. Then $12.5-\mu$ l radiolabeled RNA substrate solution containing $0.3 \mathrm{U} / \mu \mathrm{l}$ RNasin (Promega) was added to the beads and the reaction mixtures were incubated at $37^{\circ} \mathrm{C}(10 \mathrm{~min}$ for pre-tRNA, $60 \mathrm{~min}$ for viperin mRNA). The reaction was terminated by adding Trizol (Invitrogen). Subsequently, the RNA was isolated and analyzed on an $8 \%(\mathrm{v} / \mathrm{v})$ denaturing polyacrylamide gel. A phosphorimager was used to visualize the radiolabeled RNA in the gel.

Inactivation by micrococcal nuclease

Antibodies against hPop4 or pre-immune serum were coupled to Protein A-agarose beads for the immunoprecipitation of RNase MRP/P from HEp-2 cell extracts as described elsewhere [2]. The precipitates were pre-incubated in a 4 - $\mu$ l volume containing $1 \mathrm{mM} \mathrm{CaCl} 2$, or $1 \mathrm{mM}$ $\mathrm{CaCl}_{2}$ plus micrococcal nuclease $(0.5 \mathrm{U} / \mu \mathrm{l})$, or micrococcal nuclease $(0.5 \mathrm{U} / \mu \mathrm{l})$ plus $20 \mathrm{mM}$ EGTA for $15 \mathrm{~min}$ at $37^{\circ} \mathrm{C}$. Subsequently, $1 \mu \mathrm{l}$ of $0.1 \mathrm{M}$ EGTA was added. As a control, half of the reactions that had been incubated with $\mathrm{CaCl}_{2}$ and micrococcal nuclease did not receive EGTA to monitor the effect of active micococcal nuclease on the viperin substrates. After the addition of $12.5 \mu \mathrm{l}$ of $2 \times$ cleavage buffer and $7.5 \mu \mathrm{l}$ of radiolabeled substrate RNA solution containing $0.3 \mathrm{U} / \mu \mathrm{l}$ RNasin (Promega), the reaction mixtures were incubated for $1 \mathrm{~h}$ at $37^{\circ} \mathrm{C}$. RNA was then isolated and analyzed as described above.

Northern-blot hybridization

We performed Northern blotting and hybridization as described previously [2]. Hybridization with internally ${ }^{32} \mathrm{P}$-labeled antisense riboprobes against the RNA components of RNase MRP and RNase $\mathrm{P}$ was performed at $65^{\circ} \mathrm{C}$, for ${ }^{32} \mathrm{P}$-end-labeled antisense oligonucleotides complementary to U1 snRNA (5'-GCGCGAACGCAGTCCCCCA CTACCAC $\left.-3^{\prime}\right)$ at $42^{\circ} \mathrm{C}$.

Microarray analysis

We performed four independent transfections of HEp-2 cells with siRNAs against EGFP, hPop1, and Rpp40. Cells were harvested $48 \mathrm{~h}$ after transfection. Knock-down of 
hPop1 and Rpp40 was monitored by Western blotting. RNA was isolated using Trizol (Invitrogen) and purified using the RNeasy kit (Qiagen). The resulting RNAs were subjected to microarray analysis in the laboratory of Prof. Frank Holstege (Utrecht University, The Netherlands) using human 70-mer oligos (Operon, Human V2 AROS) spotted onto Codelink Activated slides (Surmodics) 21K arrays. Two sets of two biological replicates were analyzed with reverse fluorochromes. The expression profiles obtained with material of sihPop1- and siRpp40-treated cells were compared to that obtained for the control siEGFP-treated material. RNA amplifications, labeling, and hybridizations were performed as described [33]. cRNA $(2,500 \mathrm{ng})$ coupled to Cy3 and Cy5 fluorophores (Amersham) were hybridized on a Tecan HS4800PRO and scanned on an Agilent scanner (G2565BA) at $100 \%$ laser power, 30\% PMT. After data extraction using Imagene 8.0 (BioDiscovery), printtip Loess normalization was performed [34] on mean spot-intensities without background subtraction. Data was analyzed using ANOVA (R version 2.2.1/MAANOVA version 0.98-7) (http://www.r-project. org/) [35]. In a fixed-effect analysis, sample, array, and dye effects were modeled. $p$ values were determined by a permutation $* * F 2$-test, in which residuals were shuffled 5,000 times globally. Genes with $p<0.05$ after family-wise error correction were considered significantly changed. Microarray data have been deposited with ArrayExpress under Accession no. E-TABM-981.

\section{Results}

siRNA-mediated RNase MRP and RNase P depletion

To investigate whether the levels of RNase MRP in HEp-2 cells can be reduced by an siRNA-mediated knock-down approach, we transfected the cells with siRNAs against the hPop1, Rpp20, Rpp25, and Rpp40 mRNAs. Forty-eight hours after transfection the cells were lysed and the proteins were analyzed by Western blotting. The levels of each of the targeted proteins appeared to be reduced by the respective siRNA treatments, although the efficiency of knock-down varied and the siRpp25 appeared to be the least effective (Fig. 1a). Since the reduced levels of these proteins may affect the stability of the complex, we monitored the level of the RNA component of RNase MRP by Northern-blot hybridization, using U1 snRNA as a control. The reduction of hPop1, Rpp20, Rpp40 and, to a lesser extent, Rpp25, led to a concomitant decrease of RNase MRP RNA levels (Fig. 1b). These results indicate that a depletion of one of the protein components leads to destabilization and, as a result, reduced levels of the whole complex. Because the depleted proteins are also associated
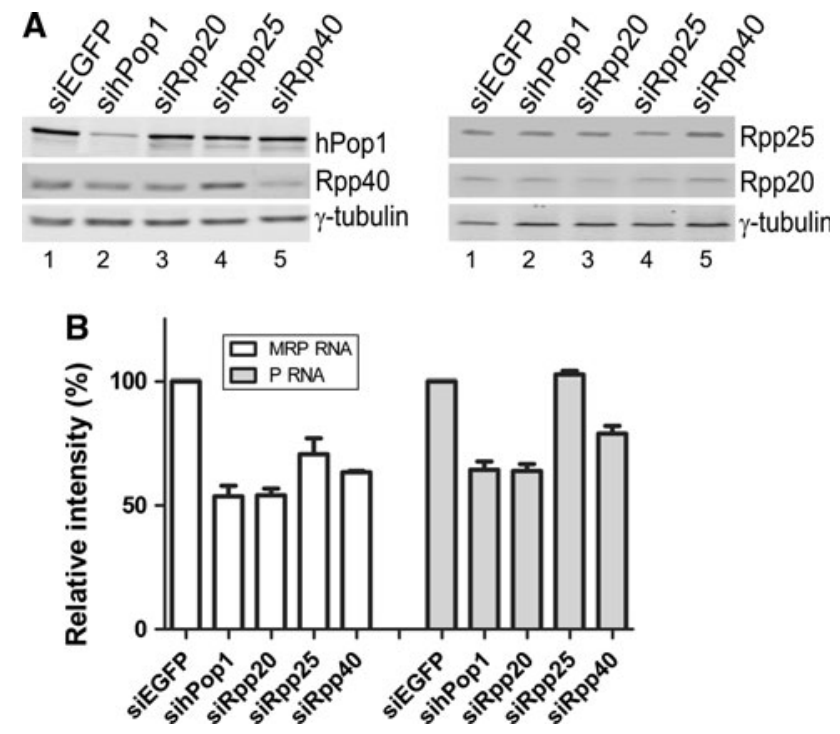

Fig. 1 siRNA-mediated knock-down of RNase MRP and P protein components leads to complex instability. a Immunoblotting using antibodies against hPop1, Rpp20, Rpp25, Rpp40, and $\gamma$-tubulin (loading control). b Northern-blot hybridization analysis of total RNA. U1 snRNA was used as a loading control and MRP and P RNA levels after siRNA treatment are depicted relative to those observed after siEGFP treatment. Results are presented as the mean of three independent experiments \pm SEM

with the RNase P complex, the effects on RNase P RNA levels were investigated as well. As expected, very similar effects were observed for the levels of RNase P RNA (Fig. 1b).

Gene expression profiles after hPop1 or Rpp40 knock-down

To identify mRNA substrates for the human RNase MRP complex, we examined the effects of siRNA-mediated depletion of RNase MRP (and RNase P) on the transcriptome of HEp-2 cells. We knocked-down the expression of two RNase MRP protein components, hPop1 and Rpp40, and after $48 \mathrm{~h}$ isolated mRNA from these cells as well as from cells transfected with an siRNA targeting the GFP mRNA (siEGFP), which was used as a control. The expression levels of mRNAs were analyzed on a genomewide scale using $21 \mathrm{~K}$ microarrays. When compared to the control, 95 genes displayed at least twofold differences after knocking-down either hPop1 or Rpp40 (Supplementary Table 1 and Supplementary Table 2 online). Seven of these were more than twofold upregulated in both datasets (RSAD2, CASP7, CAPNS1, SYPL1, H3F3A,DDT, and $A R P C 1 A)$ and four genes were more than twofold downregulated (HMOXI, NQO1, IL8, and GCLM) (Table 1). In accordance with previously reported $\mathrm{CHH}$ patient microarrays data, the differentially expressed genes are primarily associated with the immune system and apoptosis [37]. 
Table 1 Differentially expressed genes after siRNA-mediated knock-down of hPop1 or Rpp40 in HEp-2 cells compared to control transfected cells

\begin{tabular}{|c|c|c|c|c|}
\hline $\begin{array}{l}\text { Gene } \\
\text { symbol }\end{array}$ & Description & hPop1 ${ }^{\mathrm{a}}$ & $\mathrm{Rpp} 40^{\mathrm{a}}$ & GO-term biological process ${ }^{\mathrm{b}}$ \\
\hline RSAD2 & Viperin & 3.6 & 2.0 & Defense response to virus \\
\hline SYPL1 & $\begin{array}{l}\text { Synaptophysin-like } \\
\text { protein } 1\end{array}$ & 3.2 & 2.5 & Transport/synaptic transmission \\
\hline$A R P C 1 A$ & $\begin{array}{l}\text { Actin-related protein } 2 / 3 \\
\text { complex subunit } 1 \mathrm{~A}\end{array}$ & 2.5 & 2.9 & Actin cytoskeleton organization \\
\hline CASP7 & Caspase-7 precursor & 2.5 & 2.1 & Release of cytochrome c from mitochondria/apoptosis \\
\hline$H 3 F 3 A$ & Histone H3.3 & 2.5 & 2.9 & Nucleosome assembly \\
\hline$D D T$ & $\begin{array}{l}\text { D-dopachrome } \\
\text { decarboxylase }\end{array}$ & 2.4 & 2.4 & Melanin biosynthetic process from tyrosine \\
\hline CAPNS1 & Calpain small subunit 1 & 2.3 & 2.0 & Positive regulation of cell proliferation \\
\hline NQO1 & $\begin{array}{l}\mathrm{NAD}(\mathrm{P}) \mathrm{H} \text { dehydrogenase } \\
\text { [quinone] } 1\end{array}$ & -4.6 & -3.0 & $\begin{array}{l}\text { Xenobiotic metabolic process/nitric oxide biosynth. Process/response to oxidative } \\
\text { stress/synaptic cholinergic/toxin resp./neg. regulation of catalytic } \\
\text { activity/oxidation reduction }\end{array}$ \\
\hline$H M O X 1$ & Heme oxygenase 1 & -3.5 & -3.5 & Heme oxidation \\
\hline$I L 8$ & Interleukin- 8 precursor & -2.3 & -3.4 & $\begin{array}{l}\text { Angiogenesis/immune response/cell motion/inflammatory response/cell-cell } \\
\text { signaling/negative regulation of cell proliferation/cell adhesion }\end{array}$ \\
\hline$G C L M$ & $\begin{array}{l}\text { Glutamate-cysteine ligase } \\
\text { regulatory subunit }\end{array}$ & -2.0 & -2.1 & $\begin{array}{l}\text { Cysteine metabolic proc./glutathione metabolic process/neg. regulation } \\
\text { of apoptosis/regulation of blood vessel size }\end{array}$ \\
\hline
\end{tabular}

${ }^{a}$ Only genes more than twofold up- or down-regulated by both the hPop1 and Rpp40 knock-downs are shown

b GO-terms listed are from the Gene Ontology Consortium [36]

Viperin upregulation upon RNase MRP/RNase P knock-down

Direct mRNA targets for RNase MRP are predicted to be upregulated upon a reduction of RNase MRP function. Only a single mRNA was found to be upregulated more than twofold in both datasets (hPop1 and Rpp40 knockdown) as well as in four $\mathrm{CHH}$ patients, from which leukocyte mRNA was analyzed in two independent microarray studies ([37] and P. Hermanns, unpublished results). This prompted us to investigate the effects of RNase MRP on this transcript in more detail. This mRNA is transcribed from the RSAD2 gene and is translated into the anti-viral protein viperin [38]. First, we analyzed whether RNase MRP depletion affected the expression of this gene at the protein level by Western blotting. In agreement with the microarray data, the viperin protein was indeed upregulated in HEp-2 cells, not only upon siRNA-mediated knock-down of hPop1 and Rpp40, but also after knock-down of two other RNase MRP protein components, Rpp20 and Rpp25 (Fig. 2). The effects observed for depletion of the latter protein were modest, which is in agreement with the generally poor reduction in Rpp25 and RNase MRP RNA levels (Fig. 1). These results demonstrate that the expression of viperin also at the protein level is modulated by RNase MRP and/or RNase P.
Viperin upregulation is not affected by interferon

The expression of viperin is known to be induced by type I interferons [38]. Indeed, interferon- $\alpha$ (IFN- $\alpha)$ treatment of HEp-2 cells resulted in elevated viperin expression levels, which appeared to be even higher when the cells were also exposed to poly (I:C), a well-documented inducer of interferon (Fig. 3). To investigate whether viperin upregulation by RNase MRP depletion was independent of upregulation by the interferon response, we stimulated siRNA-treated HEp- 2 cells with IFN- $\alpha$ for $16 \mathrm{~h}$ prior to harvesting. Also after interferon induction the levels of both viperin protein and mRNA, as determined by quantitative RT-PCR, were elevated upon RNase MRP knock-down (Fig. 3a and data not shown). Moreover, the cumulative induction of viperin expression was also evident when the cells were exposed to both IFN- $\alpha$ and poly(I:C) (Fig. 3b). These results are consistent with the elevation of viperin expression at the transcriptional level by interferon and at the post-transcriptional level by RNase MRP.

Viperin upregulation is not due to rRNA processing defects

To exclude that viperin upregulation after RNase MRP knock-down is due to rRNA processing defects (arising from the RNase MRP knockdown), we transfected HEp-2 

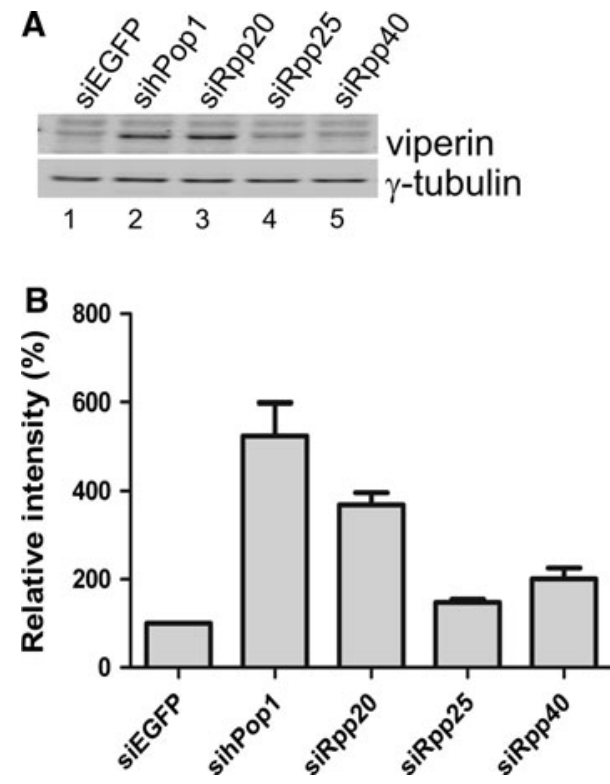

Fig. 2 Viperin protein level is upregulated after RNase MRP/P knock-down. a Western-blot analysis of viperin $48 \mathrm{~h}$ post siRNA treatment of HEp-2 cells. $\gamma$-tubulin was used as a loading control. b Viperin protein signals on the Western blots were quantified and are depicted relative to the levels observed upon treatment with the siEGFP. Results are presented as the mean of three independent experiments \pm SEM

cells with an siRNA against Mtr4, in parallel with siRNAs for EGFP, hPop1 and Rpp20. Mtr4 is an exosome-associated protein, and depletion of this protein causes the accumulation of 5.8S rRNA precursors [30]. Sixteen hours prior to harvesting of the cells, IFN- $\alpha(1,000 \mathrm{U} / \mathrm{ml})$ was added to the medium. No viperin upregulation was observed after knock-down of Mtr4 (Fig. 4). In addition, in a separate study, in which we targeted hXrn1 (a $5^{\prime}-3^{\prime}$ exoribonuclease), hDis3 (a $3^{\prime}-5^{\prime}$ exoribonuclease), hRrp41 or hPM/Scl-100 (exosome components) by siRNA in HEp- 2 cells and analyzed the effects on mRNA expression by microarrays, no upregulation of viperin mRNA was observed (unpublished data). These results strongly suggest that the observed changes in viperin expression are not due to indirect effects of interfering with RNase MRP/P function.

Viperin upregulation does not require non-coding sequences

Viperin expression cannot be induced in HeLa cells, not even after stimulation with IFN- $\alpha$ (Fig. 5a; [38]). This implies that the HeLa cell line is very suitable for transfection experiments, in which viperin is ectopically expressed, since the endogenous protein will not affect the interpretation of the results. To study the importance of coding sequence and UTRs for the regulation of viperin expression by RNase MRP/P, we transfected HeLa cells with constructs containing the viperin coding sequence either with or without the $5^{\prime}$ and $3^{\prime}$ UTRs. Subsequently, we subjected the cells to siRNA-mediated knock-down of RNase MRP/P components. Western-blot analysis of cell lysates showed that with both constructs viperin was upregulated in the siRNA treated cells (Fig. 5b). These results indicate that the induction of viperin by RNase
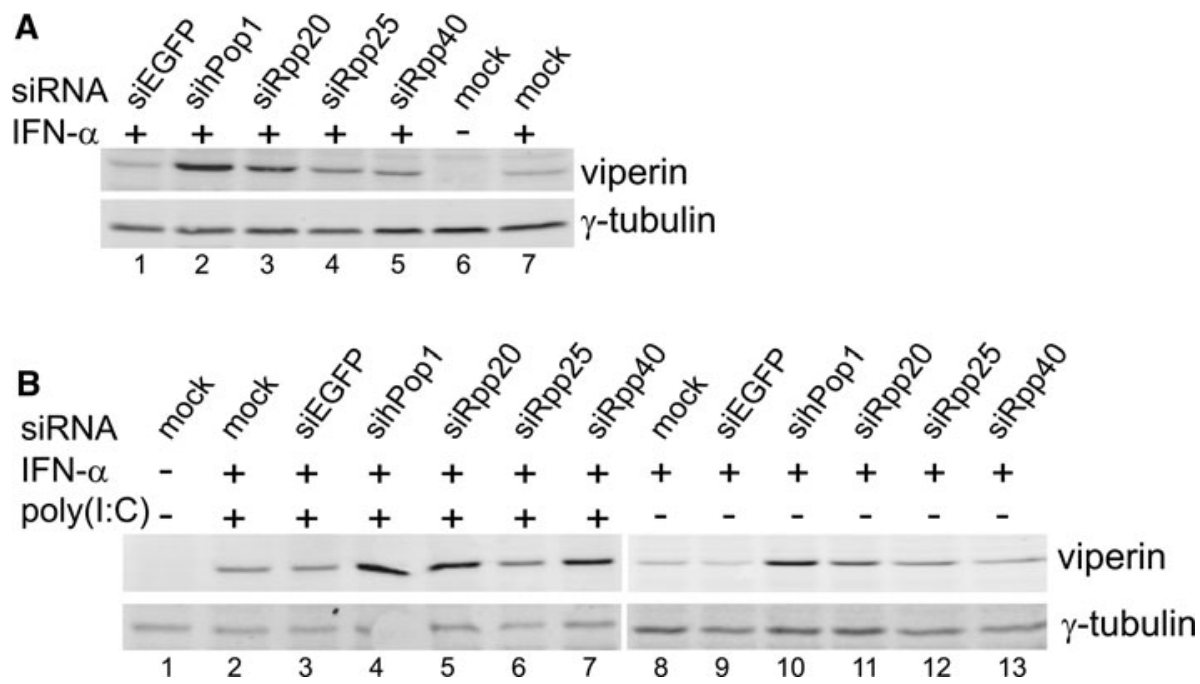

Fig. 3 Viperin upregulation by RNase MRP/P knock-down also occurs in IFN- $\alpha$ and poly(I:C) stimulated cells. a siRNA-treated HEp-2 cells were stimulated with $1,000 \mathrm{U} / \mathrm{ml} \mathrm{IFN-} \alpha 16 \mathrm{~h}$ prior to harvesting the cells. Forty-eight hours after siRNA transfection, the cells were lysed and viperin expression was analyzed by immunoblotting, using $\gamma$-tubulin as a loading control. b siRNA-treated HEp-2 cells were stimulated with $5,000 \mathrm{U} / \mathrm{ml} \mathrm{IFN}-\alpha$ and where indicated also with $100 \mu \mathrm{g} / \mathrm{ml}$ poly(I:C) $16 \mathrm{~h}$ prior to harvesting the cells. Forty-eight hours after siRNA transfection, the cells were lysed and viperin expression was analyzed by immunoblotting, using $\gamma$-tubulin as a loading control 


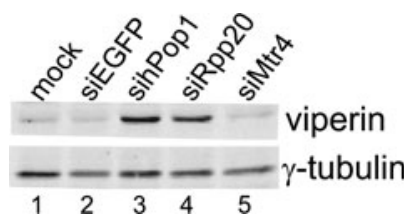

Fig. 4 Viperin upregulation is not due to rRNA processing defects. HEp-2 cells treated with the indicated siRNAs were stimulated with $1,000 \mathrm{U} / \mathrm{ml} \mathrm{IFN}-\alpha$ for $16 \mathrm{~h}$ prior to harvesting the cells. Forty-eight hours after siRNA transfection, cell lysates were analyzed by immunoblotting, using $\gamma$-tubulin as a loading control

$\mathrm{MRP} / \mathrm{P}$ knock-down is not dependent on UTR sequences and also confirm that this phenomenon does not require the promoter of the viperin gene. As a consequence, the coding sequence of viperin mRNA most likely contains the putative cleavage site(s) for RNase MRP/P.

\section{RNase MRP or RNase P cleaves viperin mRNA in vitro}

The results of transfection experiments with constructs encoding distinct parts of the 1,086-nt-long coding sequence of viperin mRNA suggested that the region targeted by RNase MRP/P is located in the central part of the coding sequence (data not shown). To investigate whether RNase MRP or RNase P are indeed capable to cleave the viperin $\mathrm{mRNA}$ in this region, we incubated radiolabeled
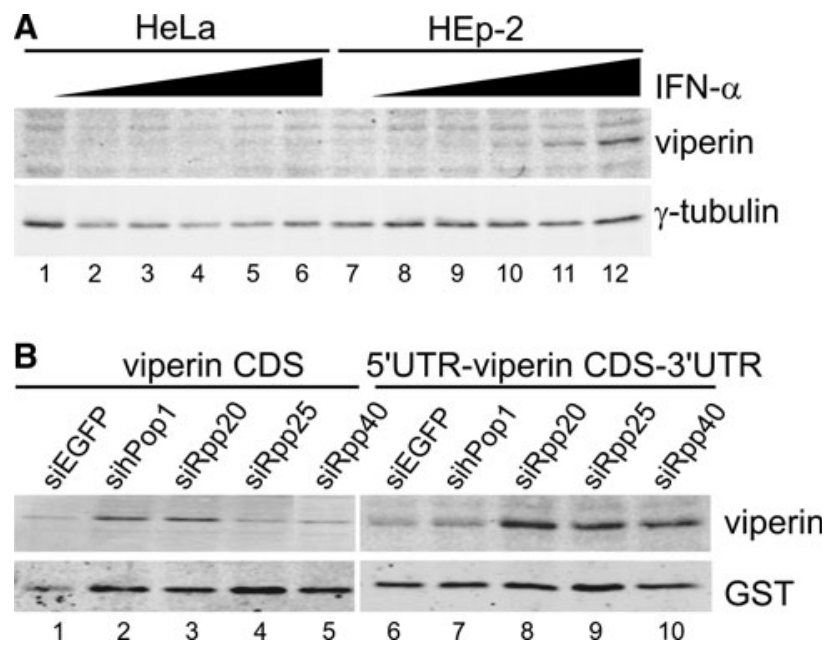

Fig. 5 The coding region of the viperin mRNA is sufficient for its elevated translation in cells depleted of RNase MRP/P. a Viperin expression in HEp-2 and HeLa cells that were subjected to increasing concentrations of IFN $\alpha$ for $16 \mathrm{~h}$ before harvesting was analyzed by immunoblotting. The concentration of IFN- $\alpha$ ranged from 0 to $1,000 \mathrm{U} / \mathrm{ml}$. As a control, $\gamma$-tubulin was analyzed in parallel. b HeLa cells were transfected with a pcDNA3.1 construct containing the coding sequence of viperin with or without the $5^{\prime}$ and $3^{\prime}$ UTRs. The cells were co-transfected with a GST-coding plasmid, which served as a transfection control. After $24 \mathrm{~h}$, the cells were treated with the indicated siRNAs. Forty-eight hours after siRNA transfection, cell lysates were analyzed by immunoblotting using antibodies specific for viperin and GST segments of the coding sequence of the viperin mRNA with RNase MRP/P in vitro. We immunoprecipitated RNase MRP and RNase P from HEp-2 cell extracts by antibodies against hPop4 and Rpp25 antibodies. As controls, we used normal rabbit serum and an antibody against the $55 \mathrm{~K}$ protein component of the U3 snoRNP in parallel. Several 100 nucleotides long viperin mRNA segments and pre-tRNA as a control were transcribed in vitro and added to the immunoprecipitates. The immunoprecipitated RNase MRP/P efficiently converted the pre-tRNA substrate in the expected products of 28 and 82 nucleotides, corresponding to the $5^{\prime}$ leader and tRNA body, respectively (Fig. 6). In three of the 100-nt viperin mRNA substrates cleavages were observed after incubation with the precipitates of the antibodies against hPop4 and Rpp25. Importantly, the corresponding cleavage products did not appear after incubation with the precipitates obtained with the normal rabbit and 55K-specific antibodies. Since two of the three cleaved substrates contained overlapping sequences, these results are consistent with the presence of two RNase MRP/P cleavage sites, one located between nucleotides 451 and 500 of the coding sequence of viperin mRNA and the other located between nucleotides 851 and 950. Additional controls with similarly sized segments of the mRNAs encoding peptidylarginine deiminase 2 and tissue transglutaminase 2, two unrelated mRNAs, the expression levels of which were not altered upon RNase MRP/P depletion (microarray data), confirmed the specificity of viperin mRNA cleavage, because no cleavage of these RNAs could be detected (results not shown).

To obtain additional evidence that the cleavage of viperin mRNA is due to the activity of RNase MRP/P, which will be dependent on its RNA component, the immunoprecipitated RNase MRP/P was pre-incubated with micrococcal nuclease (Fig. 7). Micrococcal nuclease treatment followed by inactivation of this enzyme by the addition of EGTA prior to the in vitro cleavage reaction abrogated the cleavage of viperin mRNA segments by RNase MRP/P. This effect was not due to the presence of calcium during the pre-incubation with micrococcal nuclease, nor to other activities present in the micrococcal nuclease preparation, as demonstrated by the controls. As expected, when micrococcal nuclease was not inactivated by the addition of EGTA, this enzyme led to additional cleavages in the viperin mRNA segments. Taken together, these results indicate that an intact RNA component in the RNase MRP/P preparation is essential for the cleavage activity.

\section{Discussion}

The results of this study identify the viperin mRNA as a new substrate for the human RNase MRP and/or RNase P 


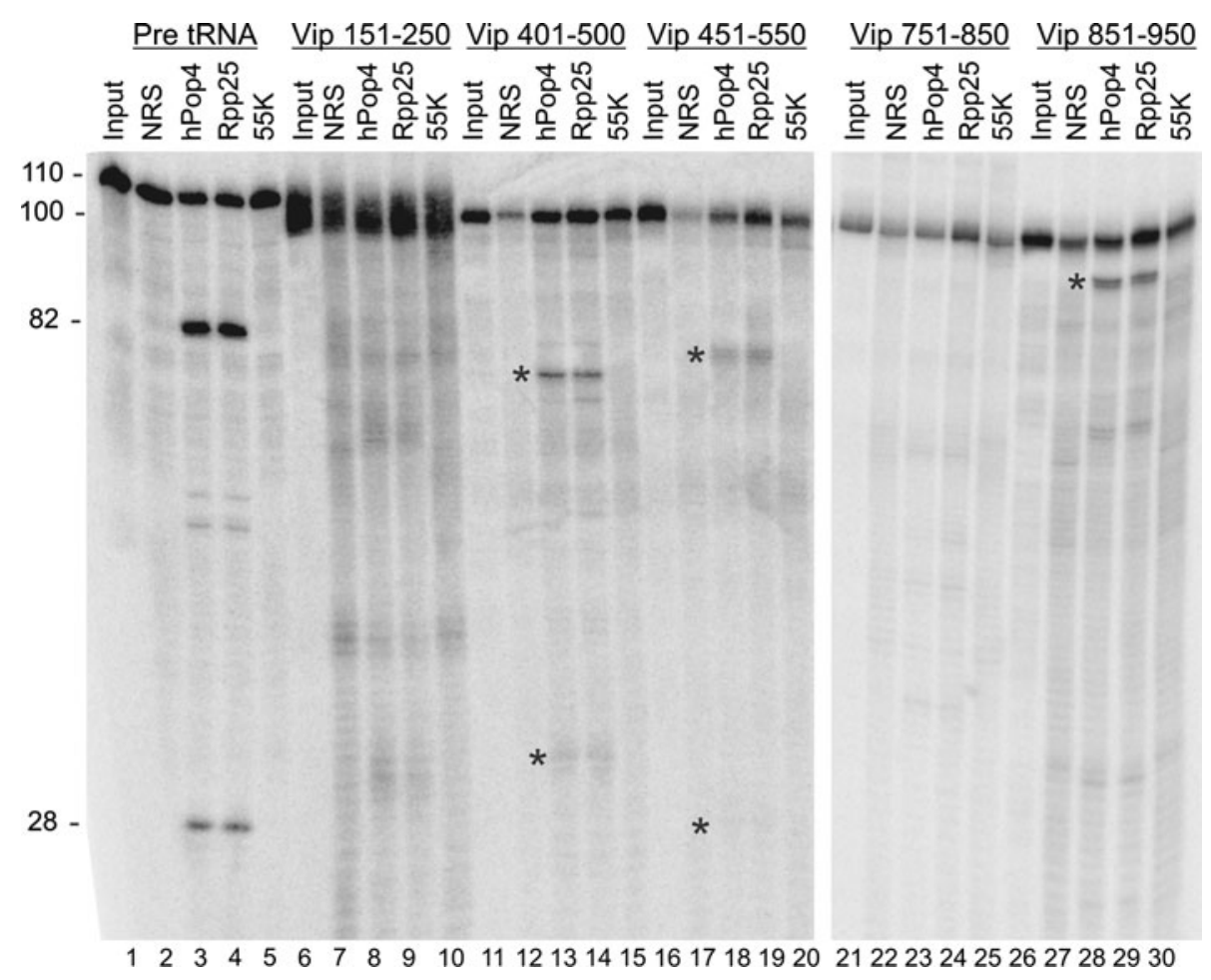

Fig. 6 Cleavage of viperin mRNA fragments by RNase MRP/P in vitro. HEp-2 cell extracts were subjected to immunoprecipitation by immobilized antibodies against hPop4, Rpp25, the U3-55K protein, and antibodies from normal rabbit serum (NRS). The resulting precipitates were incubated with pre-tRNA, which was used as a positive control and five different segments of the viperin coding sequence. Numbers indicate the $5^{\prime}$ and $3^{\prime}$ nucleotides of these

complex. We have shown that viperin expression is induced both at the protein and at the mRNA level in human cell lines after knock-down of RNase MRP- and RNase P-associated proteins. Viperin upregulation by RNase MRP/P depletion appeared to be independent of IFN- $\alpha$ and poly(I:C), two well-known inducers of interferon responsive genes, a.o. viperin. In agreement with the ribonuclease activity of RNase MRP/P, the observed induction of viperin expression is not dependent on nontranscribed elements of the viperin gene. In addition, this phenomenon does not seem to be due to specific sequence elements in the UTRs of the viperin mRNA. Taken together, our data indicate that viperin expression is repressed by RNase MRP or RNase P as a result of endoribonucleolytic cleavages in the coding sequence of the viperin mRNA.

Although the number is relatively low, our microarray data identified several other putative mRNA substrates for the human RNase MRP/P. Interestingly, the cyclin-B2 mRNA, which was reported by Thiel and coworkers to be modulated by the human RNase MRP [24], was not upregulated upon hPop1 or Rpp40 knock-down. This discrepancy will be further discussed below. Among the genes segments and correspond to their position in the coding sequence. The reaction products were analyzed by denaturing gel electrophoresis. The numbers on the left indicate the size of the pre-tRNA, $110 \mathrm{nts}$, the cleaved tRNA, $82 \mathrm{nts}$, the cleaved $5^{\prime}$ leader, $28 \mathrm{nts}$, and the viperin segments, 100 nts. The input lanes contain the radiolabeled RNAs that were not incubated with the precipitated material. The most prominent cleavage products are marked by asterisks

upregulated upon RNase MRP/P depletion a number of interferon-regulated genes can be discerned. Currently, it is unclear whether this is a common feature related to the activities of RNase MRP/P, or whether this is caused by the siRNA treatment. Interestingly, an enrichment of interferon-regulated genes was also observed in the dataset obtained with material from CHH-patient cells [37]. Future studies will clarify whether the other putative mRNA substrates are indeed modulated by RNase MRP/P and whether they are directly cleaved by this enzyme.

The in vitro cleavage experiments provide evidence for two RNase MRP/P cleavage sites in the coding sequence of the viperin mRNA. The possibility that in addition to the cleavages in the mature mRNA, also cleavages in introns present in the viperin pre-mRNA affect its expression cannot be excluded.

An important question that is not directly answered by the results of our experiments is whether the viperin mRNA is cleaved by RNase MRP or RNase P. Our strategy to reduce RNase MRP levels by siRNA-mediated knockdown of its protein components leads to the simultaneous depletion of RNase P. To distinguish between these two ribonucleases we tried to reduce their levels by siRNAs 


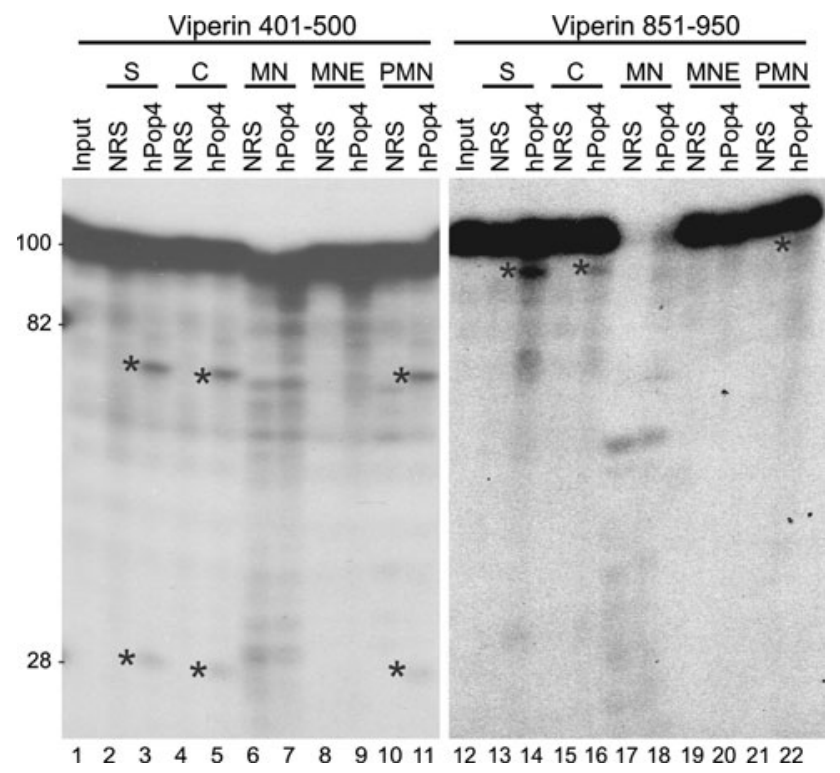

Fig. 7 The viperin mRNA cleavage activity of RNase MRP/P in vitro is nuclease-sensitive. HEp-2 cell extracts were subjected to immunoprecipitation by immobilized antibodies against hPop4 and antibodies from normal rabbit serum (NRS) as a control. The immunoprecipitates were subjected to incubation with micrococcal nuclease, as described in the "Materials and methods" section. Subsequently, the precipitates were incubated with different segments of the viperin mRNA. Numbers indicate the $5^{\prime}$ and $3^{\prime}$ nucleotides of these segments and correspond to their position in the coding sequence. The reaction products were analyzed by denaturing gel electrophoresis. The input lanes contain the radiolabeled RNAs that were not incubated with the precipitated material. $S$ standard reaction, no pre-incubation; $C$ pre-incubation with $\mathrm{CaCl}_{2}$, addition of EGTA prior to the cleavage reaction; $M N$ pre-incubation with micrococcal nuclease and $\mathrm{CaCl}_{2}$, no addition of EGTA prior to cleavage reaction; $M N E$ pre-incubation with micrococcal nuclease and $\mathrm{CaCl}_{2}$, addition of EGTA prior to cleavage reaction; $P M N$ pre-incubation with micrococcal nuclease, $\mathrm{CaCl}_{2}$, and EGTA. The most prominent cleavage products are marked by asterisks. The numbers on the left indicate the positions of a 82-nts tRNA, a 28-nts $5^{\prime}$ leader of pretRNA, and the 100-nts viperin mRNA segments

targeting their RNA components. Although, these are not mRNAs, the feasibility of this approach was recently demonstrated by Maida and colleagues [8], who used RNase MRP RNA-specific siRNAs to knock-down the levels of RNase MRP. However, none of the four siRNAs that we used, one of which corresponds to that successfully applied by Maida and colleagues, showed a significant effect on RNase MRP RNA or RNase P RNA levels (data not shown). Currently, it is unclear why the previously reported RNase MRP RNA-specific siRNA does not work in our hands. In spite of the lack of direct evidence, we propose that the post-transcriptional regulation of viperin expression is mediated by RNase MRP and not by RNase $\mathrm{P}$. This is most strongly supported by previously published observations that viperin mRNA levels are upregulated in cells from $\mathrm{CHH}$ patients, in which the function of RNase
MRP is affected as a result of mutations in the RNase MRP RNA gene, whereas the function of RNase P is unaffected [37]. In addition, the recently reported association with TERT can regulate RNase MRP RNA levels by a negativefeedback mechanism [8]. When TERT is overexpressed, RNase MRP RNA levels are downregulated. If RNase MRP, and not RNase P, controls viperin mRNA expression, this messenger is expected to be induced upon TERT overexpression. Indeed, when TERT was transduced into CD4-positive T-cells, viperin mRNA levels were elevated [39]. Future studies, in which for example the wild-type RNase MRP RNA gene in mammalian cells is replaced by a CHH-like mutant gene, will have to provide further evidence to support the involvement of RNase MRP and not that of RNase P.

The levels of RNase MRP/P as a result of knockingdown hPop1 or Rpp40 are similar to what would be expected in heterozygous carriers of RMRP promoter mutations, which display no phenotypes. The difference might be explained by the fact that, in contrast to the cells of such carriers, siRNA-treated cultured cells will show much more heterogeneity with regard to the remaining levels of RNase MRP/P. In addition, rapidly dividing cultured cells may be more critically dependent on RNase MRP/P levels than cells of such carrier individuals. In this context it is important to mention that retarded growth was indeed observed for the cells in which RNase MRP/P was downregulated. The role of RNase MRP/P in the regulation of viperin expression is further supported by the observation that the efficiency of knocking-down RNase MRP/P components inversely correlates with the efficiency of viperin upregulation (compare the results in Fig. 1 with those in Fig. 2).

RNase MRP is localized predominantly in the nucleolus, which raises the question where the viperin mRNA, and possibly other mRNAs, are cleaved by RNase MRP. In Saccharomyces cerevisiae RNase MRP has been reported to localize to specific cytoplasmic temporal asymmetric MRP bodies (TAM-bodies) after the initiation of mitosis [40]. It is possible that RNase MRP degrades specific mRNAs in these TAM-bodies. In human cells, RNase MRP components appear to be regulated in a cell-cycle dependent manner, but it is not known whether TAM bodies exist in mammalian cells as well [11]. The nucleolar association of human RNase MRP does not appear to be very strong, because upon actinomycin D treatment (to block transcription) or adenoviral infection hPop1 translocates from the nucleolus to the nucleoplasm [41, 42]. These data do not rule out the possibility that low concentrations of RNase MRP reside in the cytoplasm of human cells and that this concentration is increased upon cell physiological changes. Therefore, it is currently impossible to predict in 
which subcellular compartment the viperin mRNA is cleaved by RNase MRP.

Viperin is an anti-viral protein that is induced by type I and II interferons, LPS or viral infections [38]. It is highly conserved between mammals and lower vertebrates $[38,43]$. The expression of this protein inhibits influenza A virus release from the plasma membrane of infected cells, and also has been demonstrated to interfere with the replication of hepatitis $\mathrm{C}$ virus and human cytomegalovirus $[26,38]$. Viperin localizes to the cytoplasmic side of the endoplasmic reticulum and to lipid droplets via its $\mathrm{N}$-terminal amphiphatic $\alpha$-helix. Overexpression of viperin may lead to a crystalloid ER and has been demonstrated to reduce protein secretion from HepG2 cells $[44,45]$. The regulation of viperin expression by RNase MRP/P raises the question whether some of the symptoms of $\mathrm{CHH}$ are due to altered viperin expression levels. Viperin knockout mice show an impaired Th2 response and T-cell receptor mediated activation of NF- $\kappa \mathrm{B}$ and AP-1 [46]. In another mouse study, it was shown that viperin is expressed at higher levels in Th2 cells compared to Th1 cells [47]. These results suggest that viperin may play an important role in the immune system. An inflammatory trigger may enhance the expression of viperin via interferon signaling and this may be needed for an efficient T-cell response. Subsequently, cells might have to recover from the protein secretion inhibitory effects of viperin overexpression, by reducing the levels of viperin and this can at least in part be achieved by degradation of its mRNA. At this stage RNase MRP may become activated or may get access to the mRNAs, e.g., by a subcellular redistribution, to enhance the degradation of viperin mRNA. Interestingly, $\mathrm{CHH}$ patients indeed express higher levels of viperin in leukocytes compared to healthy controls [37].

The higher expression levels of viperin in $\mathrm{CHH}$ patient leukocytes might result in higher levels of activated NF- $\kappa \mathrm{B}$ and AP-1 as well. Constitutive NF- $\kappa \mathrm{B}$ activation has been observed in various hematological malignancies and solid tumors [48]. Although it remains to be demonstrated, it is tempting to speculate that the possibly elevated levels of active NF- $\kappa \mathrm{B}$ due to higher viperin expression in $\mathrm{CHH}$ patient $\mathrm{T}$-cells are associated with the increased risk to develop hematological cancers.

In rats, the viperin homolog BEST5 is expressed in bone-forming osteoblast cells during their differentiation [49]. This suggests that viperin plays a role in the proliferation or differentiation of osteoblasts. No viperin induction was seen in rat chondrocytes. Chondrocytes are cells that differentiate into mineralized hypertrophic chondrocytes before undergoing apoptosis. Osteoblasts and osteoclasts then remodulate the remaining mineralized matrix leading to bone deposition. Since RNase MRP is strongly upregulated in mouse hypertrophic chondrocytes, and because of the short-limbed dwarfism phenotype of $\mathrm{CHH}$, it is expected to exert an important function in these cells [37]. In spite of these observations, more research is required to investigate whether the deregulation of viperin expression is involved in the dwarfism phenotype of $\mathrm{CHH}$.

In accordance with the $\mathrm{CHH}$ patient microarrays data mentioned above, the dataset of our microarray analyses did not show upregulation of human B-type cyclins after RNase MRP depletion. In addition, we have examined several $\mathrm{CHH}$ patient-derived fibroblasts and fibroblasts from their relatives, and did not find altered cyclin-B1 or cyclin-B2 expression levels (unpublished data). Thiel and coworkers have transfected healthy human fibroblasts with constructs encoding different RNase MRP RNA mutants and analyzed the cyclin-B2 mRNA levels by quantitative RT-PCR. Their results showed that transient expression of the 70A $>$ G mutant of RNase MRP RNA significantly increased the expression of the cyclin-B2 mRNA. Interestingly, for most other mutations tested, they observed a decrease in cyclin-B2 mRNA levels [25]. Taken together, these data do not support a role for RNase MRP in the regulation of B-type cyclin expression in human cells.

We conclude that the present study for the first time provides direct evidence for the cleavage of a mRNA by a human small nucleolar ribonucleoprotein complex. Cleavage of the viperin mRNA by RNase MRP/P regulates the expression of viperin post-transcriptionally and the altered expression levels of viperin upon a reduction of RNase MRP activity may be directly involved in the pathogenesis of $\mathrm{CHH}$.

Acknowledgments We thank F. Holstege, M. Groot-Koerkamp, and D. van Leenen (University of Utrecht, The Netherlands) for their help with the microarray analyses, S. Altman (Yale University, New Haven, USA) for providing us with antibodies against RNase MRP proteins, and $\mathrm{H}$. Pluk for helpful discussions. This work was supported in part by the Netherlands Organization for Scientific Research (NWO-CW).

Open Access This article is distributed under the terms of the Creative Commons Attribution Noncommercial License which permits any noncommercial use, distribution, and reproduction in any medium, provided the original author(s) and source are credited.

\section{References}

1. Pluk H, van Eenennaam H, Rutjes SA, Pruijn GJ, van Venrooij WJ (1999) RNA-protein interactions in the human RNase MRP ribonucleoprotein complex. RNA 5:512-524

2. Welting TJ, Kikkert BJ, van Venrooij WJ, Pruijn GJ (2006) Differential association of protein subunits with the human RNase MRP and RNase P complexes. RNA 12:1373-1382

3. Welting TJ, van Venrooij WJ, Pruijn GJ (2004) Mutual interactions between subunits of the human RNase MRP ribonucleoprotein complex. Nucleic Acids Res 32:2138-2146 
4. Chang DD, Clayton DA (1987) A novel endoribonuclease cleaves at a priming site of mouse mitochondrial DNA replication. EMBO J 6:409-417

5. Lygerou Z, Allmang C, Tollervey D, Seraphin B (1996) Accurate processing of a eukaryotic precursor ribosomal RNA by ribonuclease MRP in vitro. Science 272:268-270

6. Lindahl L, Bommankanti A, Li X, Hayden L, Jones A, Khan M, Oni T, Zengel JM (2009) RNase MRP is required for entry of 35S precursor rRNA into the canonical processing pathway. RNA 15:1407-1416

7. Gill T, Cai T, Aulds J, Wierzbicki S, Schmitt ME (2004) RNase MRP cleaves the CLB2 mRNA to promote cell cycle progression: novel method of mRNA degradation. Mol Cell Biol 24:945-953

8. Maida Y, Yasukawa M, Furuuchi M, Lassmann T, Possemato R, Okamoto N, Kasim V, Hayashizaki Y, Hahn WC, Masutomi K (2009) An RNA-dependent RNA polymerase formed by TERT and the RMRP RNA. Nature 461:230-235

9. Robertson HD, Altman S, Smith JD (1972) Purification and properties of a specific Escherichia coli ribonuclease which cleaves a tyrosine transfer ribonucleic acid precursor. J Biol Chem 247:5243-5251

10. Reiner R, Ben-Asouli Y, Krilovetzky I, Jarrous N (2006) A role for the catalytic ribonucleoprotein RNase $\mathrm{P}$ in RNA polymerase III transcription. Genes Dev 20:1621-1635

11. Reiner R, Krasnov-Yoeli N, Dehtiar Y, Jarrous N (2008) Function and assembly of a chromatin-associated RNase $\mathrm{P}$ that is required for efficient transcription by RNA polymerase I. PLoS ONE 3:e4072

12. Walker SC, Engelke DR (2006) Ribonuclease P: the evolution of an ancient RNA enzyme. Crit Rev Biochem Mol Biol 41:77-102

13. McKusick VA, Eldridge R, Hostetler JA, Ruangwit U, Egeland JA (1965) Dwarfism in the Amish. II. Cartilage-hair hypoplasia. Bull Johns Hopkins Hosp 116:285-326

14. Ridanpää M, van Eenennaam H, Pelin K, Chadwick R, Johnson C, Yuan B, van Venrooij W, Pruijn G, Salmela R, Rockas S, Mäkitie O, Kaitila I, de la Chapelle A (2001) Mutations in the RNA component of RNase MRP cause a pleiotropic human disease: cartilage-hair hypoplasia. Cell 104:195-203

15. Taskinen M, Ranki A, Pukkala E, Jeskanen L, Kaitila I, Makitie O (2008) Extended follow-up of the Finnish cartilage-hair hypoplasia cohort confirms high incidence of non-Hodgkin lymphoma and basal cell carcinoma. Am J Med Genet A 146A:2370-2375

16. Makitie O, Pukkala E, Kaitila I (2001) Increased mortality in cartilage-hair hypoplasia. Arch Dis Child 84:65-67

17. Makitie O, Kaitila I (1993) Cartilage-hair hypoplasia-clinical manifestations in 108 Finnish patients. Eur J Pediatr 152:211-217

18. Makitie O, Kaitila I, Savilahti E (2000) Deficiency of humoral immunity in cartilage-hair hypoplasia. J Pediatr 137:487-492

19. Toiviainen-Salo S, Kajosaari M, Piilonen A, Makitie O (2008) Patients with cartilage-hair hypoplasia have an increased risk for bronchiectasis. J Pediatr 152:422-428

20. Makitie O, Rajantie J, Kaitila I (1992) Anaemia and macrocytosis-unrecognized features in cartilage-hair hypoplasia. Acta Paediatr 81:1026-1029

21. Thiel CT, Mortier G, Kaitila I, Reis A, Rauch A (2007) Type and level of RMRP functional impairment predicts phenotype in the cartilage hair hypoplasia-anauxetic dysplasia spectrum. Am J Hum Genet 81:519-529

22. Kavadas FD, Giliani S, Gu Y, Mazzolari E, Bates A, Pegoiani E, Roifman CM, Notarangelo LD (2008) Variability of clinical and laboratory features among patients with ribonuclease mitochondrial RNA processing endoribonuclease gene mutations. J Allergy Clin Immunol 122:1178-1184

23. Notarangelo LD, Roifman CM, Giliani S (2008) Cartilage-hair hypoplasia: molecular basis and heterogeneity of the immunological phenotype. Curr Opin Allergy Clin Immunol 8:534-539

24. Rider NL, Morton DH, Puffenberger E, Hendrickson CL, Robinson DL, Strauss KA (2009) Immunologic and clinical features of 25 Amish patients with RMRP 70 A- $>$ G cartilage hair hypoplasia. Clin Immunol 131:119-128

25. Thiel CT, Horn D, Zabel B, Ekici AB, Salinas K, Gebhart E, Ruschendorf F, Sticht H, Spranger J, Müller D, Zweier C, Schmitt ME, Reis A, Rauch A (2005) Severely incapacitating mutations in patients with extreme short stature identify RNAprocessing endoribonuclease RMRP as an essential cell growth regulator. Am J Hum Genet 77:795-806

26. Wang X, Hinson ER, Cresswell P (2007) The interferon-inducible protein viperin inhibits influenza virus release by perturbing lipid rafts. Cell Host Microbe 2:96-105

27. Van Eenennaam H, Pruijn GJ, van Venrooij WJ (1999) hPop4: a new protein subunit of the human RNase MRP and RNase $\mathrm{P}$ ribonucleoprotein complexes. Nucleic Acids Res 27: 2465-2472

28. Granneman S, Pruijn GJ, Horstman W, van Venrooij WJ, Luhrmann R, Watkins NJ (2002) The hU3-55K protein requires $15.5 \mathrm{~K}$ binding to the box $\mathrm{B} / \mathrm{C}$ motif as well as flanking RNA elements for its association with the U3 small nucleolar RNA in Vitro. J Biol Chem 277:48490-48500

29. Welting TJ, Peters FM, Hensen SM, van Doorn NL, Kikkert BJ, Raats JM, van Venrooij WJ, Pruijn GJ (2007) Heterodimerization regulates RNase MRP/RNase $\mathrm{P}$ association, localization, and expression of Rpp20 and Rpp25. RNA 13:65-75

30. Schilders G, van Dijk E, Pruijn GJ (2007) C1D and hMtr4p associate with the human exosome subunit PM/Scl-100 and are involved in pre-rRNA processing. Nucleic Acids Res 35:2564-2572

31. Sanchez I, Hughes RT, Mayer BJ, Yee K, Woodgett JR, Avruch J, Kyriakis JM, Zon LI (1994) Role of SAPK/ERK kinase-1 in the stress-activated pathway regulating transcription factor c-Jun. Nature 372:794-798

32. Krupp G, Cherayil B, Frendewey D, Nishikawa S, Soll D (1986) Two RNA species co-purify with RNase P from the fission yeast Schizosaccharomyces pombe. EMBO J 5:1697-1703

33. Roepman P, Wessels LFA, Kettelarij N, Kemmeren P, Miles AJ, Lijnzaad P, Tilanus MGJ, Koole R, Hordijk G, van der Vliet PC, Reinders MJT, Slootweg PJ, Holstege FCP (2005) An expression profile for diagnosis of lymph node metastases from primary head and neck squamous cell carcinomas. Nat Genet 37:182-186

34. Yang YH, Dudoit S, Luu P, Lin DM, Peng V, Ngai J, Speed TP (2002) Normalization for cDNA microarray data: a robust composite method addressing single and multiple slide systematic variation. Nucleic Acids Res 30:e15

35. Wu H, Kerr MK, Cui X, Churchill GA (2002) MAANOVA: a software package for the analysis of spotted cDNA microarray experiments. In: Parmigiani G, Garrett ES, Irizarry RA, Zeger SL (eds) The analysis of gene expression data: methods and software. Springer, Berlin Heidelberg New York, 504 pp

36. Ashburner M, Ball CA, Blake JA, Botstein D, Butler H, Cherry JM, Davis AP, Dolinski K, Dwight SS, Eppig JT, Harris MA, Hill DP, Issel-Tarver L, Kasarskis A, Lewis S, Matese JC, Richardson JE, Ringwald M, Rubin GM, Sherlock G (2000) Gene ontology: tool for the unification of biology. The Gene Ontology Consortium. Nat Genet 25:25-29

37. Hermanns P, Bertuch AA, Bertin TK, Dawson B, Schmitt ME, Shaw C, Zabel B, Lee B (2005) Consequences of mutations in the non-coding RMRP RNA in cartilage-hair hypoplasia. Hum Mol Genet 14:3723-3740

38. Chin KC, Cresswell P (2001) Viperin cig5, an IFN-inducible antiviral protein directly induced by human cytomegalovirus. Proc Natl Acad Sci USA 98:15125-15130 
39. Roth A, Baerlocher GM, Schertzer M, Chavez E, Duhrsen U, Lansdorp PM (2005) Telomere loss, senescence, and genetic instability in CD4 $+\mathrm{T}$ lymphocytes overexpressing hTERT. Blood 106:43-50

40. Gill T, Aulds J, Schmitt ME (2006) A specialized processing body that is temporally and asymmetrically regulated during the cell cycle in Saccharomyces cerevisiae. J Cell Biol 173:35-45

41. Andersen JS, Lam YW, Leung AK, Ong SE, Lyon CE, Lamond AI, Mann M (2005) Nucleolar proteome dynamics. Nature 433:77-83

42. Lam YW, Evans VC, Heesom KJ, Lamond AI, Matthews DA (2010) Proteomics analysis of the nucleolus in adenovirusinfected cells. Mol Cell Proteomics 9:117-130

43. Jiang D, Guo H, Xu C, Chang J, Gu B, Wang L, Block TM, Guo JT (2008) Identification of three interferon-inducible cellular enzymes that inhibit the replication of hepatitis $\mathrm{C}$ virus. J Virol 82:1665-1678

44. Hinson ER, Cresswell P (2009) The antiviral protein, viperin, localizes to lipid droplets via its N-terminal amphipathic alphahelix. Proc Natl Acad Sci USA 106:20452-20457
45. Hinson ER, Cresswell P (2009) The N-terminal amphipathic \{alpha\}-helix of viperin mediates localization to the cytosolic face of the endoplasmic reticulum and inhibits protein secretion. J Biol Chem 284:4705-4712

46. Qiu LQ, Cresswell P, Chin KC (2009) Viperin is required for optimal Th2 responses and $\mathrm{T}$ cell receptor-mediated activation of NF- $\{$ kappa $\}$ B and AP-1. Blood 113:3520-3529

47. Hata M, Takahara S, Tsuzaki H, Ishii Y, Nakata K, Akagawa KS, Satoh K (2009) Expression of Th2-skewed pathology mediators in monocyte-derived type 2 of dendritic cells DC2. Immunol Lett 126:29-36

48. Baud V, Karin M (2009) Is NF-kappaB a good target for cancer therapy? Hopes and pitfalls. Nat Rev Drug Discov 8:33-40

49. Grewal TS, Genever PG, Brabbs AC, Birch M, Skerry TM (2000) Best5: a novel interferon-inducible gene expressed during bone formation. FASEB J 14:523-531 